\title{
Correction of an important typographical error in the European Association of Nuclear Medicine (EANM) guidelines
}

\author{
Elizabeth Anne Anderson
}

Received: 19 December 2011 / Accepted: 5 January 2012 /Published online: 1 February 2012

(C) Springer-Verlag 2012

Dear Sir,

Complete thyroid blockade is required prior to the administration of ${ }^{131}$ I-metaiodobenzylguanidine ( $\left.{ }^{131} \mathrm{I}-\mathrm{MIBG}\right)$. Insufficient iodine prophylaxis may increase long-term adverse effects, especially the development of hypothyroidism or thyroid malignancy $[1,2]$.

The European Association of Nuclear Medicine (EANM) procedure guideline for ${ }^{131}$ I-MIBG therapy includes information about performing this treatment and dosing recommendations to achieve thyroid blockade using a range of oral stable iodine presentations [3].

Table 1 in the EANM procedure guideline recommends Lugol's Solution 1\% 40 drops (being 20 drops twice daily) for thyroid blockade. All concentrations of Lugol's Solution are presumed to contain approximately 20 drops in $1 \mathrm{ml}$ as they are aqueous solutions. A dosage of 40 drops Lugol's Solution $1 \%$ would contain $52 \mathrm{mg}$ iodine, which is approximately half the recommended amount of iodine required for an adult to achieve complete thyroid blockade [4, 5].

In order to administer equivalent iodine quantities as other agents in Table 1, a dosage of 40 drops (20 drops twice daily) of Lugol's Solution $2 \%$ would be required.

Lugol's Solution contains 5\% iodine and 10\% potassium iodide in aqueous solution. Lugol's Solution is also known as Aqueous Iodine Oral Solution BP 2011 or Strong Iodine Solution USP 34 [6]. In Australia, our pharmaceutical formulary contains the formula for Lugol's Solution [7]. This solution contains $130 \mathrm{mg} / \mathrm{ml}$ total iodine [6].

The use of various concentrations of Lugol's Solution has become accepted practice in a number of countries. Great care is required to ensure an understanding of the formulation of

\section{E. A. Anderson $(\square)$}

Medicines Information Service, Department of Pharmacy,

Westmead Hospital,

Westmead, Sydney, NSW 2145, Australia

e-mail: Elizabeth_anderson@wsahs.nsw.gov.au the solution when a percentage concentration is used. When terms such as \% are used it is important to state the dimensionless quantity whose value is being specified [8]. Scientifically, a percentage concentration of a solution refers to a quantity of solute in a definite volume of solution. However, concentrations of Lugol's Solution refer to the concentration of iodine contained in the solution, not the total iodine content.

Pharmacists may assist with clarification of concentrations such as the amount of iodine present in various formulations, based upon their training in pharmaceutics and their familiarity with the composition of solutions.

\section{References}

1. van Santen HM, de Kraker J, van Eck BLF, de Vijlder JJM, Vulsma $T$. High incidence of thyroid dysfunction despite prophylaxis with potassium iodide during (131)I-meta-iodobenzylguanidine treatment in children with neuroblastoma. Cancer 2002;94:2081-9.

2. US Department of Health and Human Services Food and Drug Administration Center for Drug Evaluation and Research (CDER). Guidance on potassium iodide as a thyroid blocking agent in radiation emergencies. December 2001. http://www.fda.gov/downloads/ Drugs/GuidanceComplianceRegulatoryInformation/Guidances/ UCM080542.pdf. Accessed 18 Sep 2011.

3. Giammarile F, Chiti A, Lassmann M, Brans B, Flux G. EANM procedure guidelines for 131I-meta-iodobenzylguanidine (131ImIBG) therapy. Eur J Nucl Med Mol Imaging 2008;35:1039-47.

4. US Department of Health and Human Services. Potassium iodide. Radiation emergency medical management guidance on diagnosis and treatment for health care providers. http://www.remm.nlm.gov/ potassiumiodide.htm\#prescribe. Accessed 20 Nov 2011.

5. Centers for Disease Control and Prevention. Potassium iodide (KI). http://emergency.cdc.gov/radiation/ki.asp. Accessed 20 Nov 2011.

6. Sweetman SC, editor. Martindale: the complete drug reference. 37 th ed. London: Pharmaceutical Press; 2011.

7. Sansom LN, editor. Australian pharmaceutical formulary and handbook. 21st ed. Canberra: Pharmaceutical Society of Australia; 2009.

8. Bureau International des Poids et Mesures. The International System of Units (SI). 8th ed. 2006. 